\title{
Indicadores para Avaliação do Processo de Expansão da Pastagem no Pantanal de Cáceres/MT
}

\author{
Indicators to Assess Pasture Expansion Process in the Pantanal of Cáceres /MT
}

\author{
Indicadores para Evaluación del Proceso de Expansión de la Pastagen en el \\ Pantanal de Cáceres MT
}

\author{
Helibera Rita Ramos Capistrano de Aquino ${ }^{1}$ \\ Edinéia Aparecida dos Santos Galvanin ${ }^{2}$ \\ Sandra Mara Alves da Silva $\mathrm{Neves}^{3}$
}

\begin{abstract}
RESUMO: Este trabalho tem como objetivo utilizar indicadores para avaliar o processo de expansão da pastagem no Pantanal de Cáceres-Mato Grosso, no período de 1999 a 2014. Realizou-se uma análise espaço-temporal dos últimos 15 anos, com intervalo de tempo de cinco anos, por meio de imagens do Landsat 5 e Landsat 8. Três classes de uso da terra foram mapeadas: Vegetação Natural Florestal, Pastagem e Savana Arborizada + Savana Gramíneo-Lenhosa. As classes geradas possibilitaram o cálculo dos índices para a determinação de um cenário ambiental na área de estudo. Os indicadores mostraram um aumento crescente da área pastagem, na ordem de $182,34 \%$ para o Índice de Ocupação de Pastagem e 23,08\% para Índice de Expansão de Pastagem até o ano de 2014 e demonstraram que a supressão da Vegetação Natural Florestal é maior que a supressão da Savana Arborizada + Savana Gramíneo Lenhosa. A oscilação dos índices no período de estudo pode ser atribuída à ocorrência de queimadas, secas, cheias e vazão. Os indicadores apontaram que, apesar da expansão da pastagem, o Pantanal de Cáceres é uma região que apresenta uma dinâmica ambiental complexa, rica e diversificada, o que sugere a necessidade de monitoramento constante para verificação de ações antrópicas que ameaçam seu equilíbrio ambiental.
\end{abstract}

PALAVRAS-CHAVE: Áreas úmidas; Bioinvasão; Uso da terra.

ABSTRACT: This work aims to use indicators to assess the pasture expansion process in the Pantanal of Cáceres-Mato Grosso, from 1999 to 2014. A spatiotemporal analysis of the past 15 years was carried out with time interval of 5 years, through images of Landsat 5 and Landsat 8 . Three land use classes were mapped: Natural Forest Vegetation, Pasture and Forested Savannah + GrassyWoody Savannah. The generated classes enable the calculation of indices for the determination of an environmental scenario in the study area. The indicators showed a growing increase in pasture area in the order of 182.34\% to Pasture Occupation Index and 23.08\% to Pasture Expansion Index until 2014 and showed that the suppression of Natural Forest Vegetation is greater than the suppression of Forested Savannah and Grassy-Woody Savannah. The oscillation of the indices during the study period can be attributed to the occurrences of forest fires, droughts, floods and flow. The indicators showed that despite the pasture expansion, the Pantanal of Cáceres is a region with a complex

\footnotetext{
${ }^{1}$ IFMT, Rua Professora Zumira Canavarros, 93 - Centro, Cuiabá - MT, 78005-200, helibera @yahoo.com.br.

${ }^{2}$ UNEMAT, R. A, s/n - COHAB São Raimundo, Barra do Bugres - MT, 78390-000, galvinin@gmail.com.

${ }^{3}$ UNEMAT, Av. São João, S/N - Cavalhada, Cáceres - MT, 78200-000, ssneves@unemat.br.
} 
environmental dynamic, enriched and diversified, suggesting the need for constant monitoring to check human actions that threaten its environmental balance.

KEYWORDS: Wetlands; Bioinvasion; Land use.

RESUMEN: Este trabajo tiene como objetivo utilizar indicadores para evaluar el proceso de expansión del pastoreo en el Pantanal de Cáceres-Mato Mrosso, en el período de 1999 a 2014. Se realizó un análisis espacio-temporal de los últimos 15 años, con intervalo de tiempo de cinco años, por medio de imágenes del Landsat 5 y Landsat 8. Tres clases de uso de la tierra fueron mapeadas: Vegetación Natural Forestal, Pasto y Savana Arborizada + Savana Gramíneo-Lenhosa. Las clases generadas posibilitar el cálculo de los índices para la determinación de un escenario ambiental en el área de estudio. Los indicadores mostraron un aumento creciente del área pastoreo en el orden de 182,34\% para el Índice de Ocupación de Pastoreo y el 23,08\% para Índice de Expansión de Pasto hasta el año 2014 y demostraron que la supresión de la Vegetación Forestal es más grande que la supresión de la Savana Arborizada Savana Gramíneo Leñosa. La oscilación de los índices en el período de estudio puede ser atribuida a la ocurrencia de quemas, sequías, inundaciones y salida. Los indicadores apuntaron que, a pesar de la expansión del pastoreo, el Pantanal de Cáceres es una región que presenta una dinámica ambiental compleja, rica y diversificada, lo que sugiere la necesidad de un monitoreo constante para la verificación de acciones antrópicas que amenazan su equilibrio ambiental.

PALABRAS CLAVES: Áreas húmedas; Bioinvasión; Uso de la tierra.

\section{INTRODUÇÃO}

De acordo com o Zoneamento Sócio-Econômico Ecológico do estado de Mato Grosso (ZSEE), o Pantanal de Cáceres está inserido em uma região de planejamento cuja unidade socioeconômica é classificada como uma Zona de Uso Sustentável e está avaliada com baixa e média-baixa sustentabilidade. $O$ documento também descreve o desenvolvimento agropecuário como uma das principais aptidões da região (MATO GROSSO, 2004).

O desenvolvimento, principalmente, da pecuária bovina se deve às suas condições edafoclimáticas favoráveis e à vegetação característica que lhe confere um ambiente ímpar (EMBRAPA, 2006; MATO GROSSO, 2010).

A vegetação presente no Pantanal é composta por fitofisionomias diversificadas que sofrem influência de outros biomas, tais como a Mata Atlântica, Floresta Amazônica, Cerrado e o Chaco Boliviano (ABREU; ROSA, 2007; BRASIL, 2014; FERNANDES; SIGNOR; PENHA, 2010). Apesar da diversidade fitofisionômica, destaca-se como vegetação predominante a Savana Gramíneo-Lenhosa, que representa $31,1 \%$ da região. Esta se caracteriza por formar campos com ou sem arbustos e subarbustos, esparsos ou densos, variando de acordo com o nível de inundação. Os campos que se formam apresentam um conjunto de espécies de gramíneas nativas diferentes das quais se destacam a grama-do-cerrado (Mesosetumchaseae), capim-fura-bucho (Paspalumlineare), 
capim corona (Elionurusmuticus) e capim vermelho (Andropogonhypogynus) (SILVA et al., 2011).

Pott e Pott (1996) identificaram pelo menos 212 espécies de gramíneas de ampla distribuição e, apesar da variedade, existe uma predominância geral de espécie de Savana e essa pode ser aproveitada para o pastejo.

Apesar de ser uma região propícia ao desenvolvimento da atividade pecuária e obter destaque no cenário estadual pelo bom desempenho no ranking de produção de bovinos dos últimos anos (MATO GROSSO, 2010), também está sendo ameaçada por falta de um sistema sustentável de uso, pois, para obter o aumento da produtividade, produtores introduzem forrageiras exóticas, atribuindo às pastagens nativas baixo valor de qualidade e produtividade (SANTOS et al., 2005). A prática de pastos cultivados para aumento da produtividade do rebanho se repete há mais de três décadas na região do Pantanal (COMASTRI FILHO, 1997; CRISPIM; BARIONI JUNIOR; BRANCO, 2000).

A atividade econômica desenvolvida na região merece atenção especial. Responsável pela maior parte da supressão de vegetação nativa dos diferentes biomas, a pecuária bovina ainda promove a inserção de gramíneas exóticas que disseminam e competem com as nativas, comportando-se como espécie invasora (GUGLIERI; CAPORAL; SIAMARELI, 2009). Da mesma forma, Freitas et al. (2011) descrevem que é crescente a pressão antrópica sobre as florestas naturais. A frequente conversão dessas áreas em pastagens e agricultura faz surgir a necessidade de uma análise em séries temporais para melhor avaliar os impactos.

Gramíneas exóticas de forma geral interferem na dinâmica natural do ambiente no qual foram inseridas e prejudicam principalmente as espécies herbáceas (FREITAS; PIVELLO, 2005). Segundo Rebellato (2010), as herbáceas se distribuem de forma diferente por todo gradiente de inundação, apresentam diferentes intensidades de tolerância ao estresse hídrico e são consideradas indicadoras de ambientes com sazonalidade, pois devido a seus curtos ciclos de vida, estratégias reprodutivas e rápidas respostas às mudanças nas condições hídricas locais, apresentam-se sensíveis às mudanças na dinâmica da vegetação.

Segundo Rodrigues (2002) a invasão de espécies exóticas no Pantanal pode ameaçar a sobrevivência de mamíferos, pois estes geralmente ocupam o topo da cadeia e dependem dos ambientes preservados para sua sobrevivência e de suas presas.

A Savana Gramíneo-Lenhosa está associada às áreas de drenagens ou depressões, apresentando-se sensível aos processos de intervenção antrópica (BOVE et al., 2003). Quando substituída para expansão de áreas de pastagens, a Savana Gramíneo-Lenhosa é suprimida pelas forrageiras exóticas que apresentam potencial de ocupação, dispersão e 
disseminação espontânea, se comportando como invasoras com potencial de colonização e competindo com espécies nativas, ameaçando o equilíbrio natural da região (GUGLIERI; CAPORAL; SIAMARELI, 2009).

Nesse sentido, houve alteração do Pantanal, por ação antrópica, dos 11,54\% de sua vegetação $10,92 \%$ são utilizados para o desenvolvimento da atividade pecuarista (BRASIL, 2014); dessa forma Santos et al. (2005) salienta a importância de sua preservação e conservação.

Os impactos dessa prática afetam de forma considerável a biodiversidade da planície pantaneira, as gramíneas exóticas introduzidas em ecossistemas interferem em toda sua dinâmica uma vez que introduzidas em condições ecológicas semelhantes às de seus habitats de origem facilmente se disseminam (BRASIL, 1994; FREITAS, 1999).

Regiões formadas por áreas úmidas de importância internacional, como o Pantanal, que se encontram ameaçadas, devem ser protegidas, e também se deve promover o controle de ameaças em potencial como as espécies invasoras. Isto destaca a importância do desenvolvimento de pesquisa, manejo e planos de gestão para minimizar a propagação dos impactos, segundo a Convenção de Ramsar (BRASIL, 2007).

Uma das formas de contribuir para a preservação do Pantanal é promover estudos de cunho ambiental, construindo um sistema de indicadores que quantifique e avalie $o$ desempenho ambiental, promovendo o monitoramento dessa área, possibilitando identificar possíveis ameaças, fazer previsões e discutir ações preventivas, tais como políticas públicas de preservação. Segundo Figueiredo (1996) a utilização de indicadores permite avaliar o estado do ambiente e a sua evolução ao longo do tempo.

Nesse contexto, desenvolver estudos que busquem alternativas e avaliem os impactos do desenvolvimento da atividade na planície pantaneira pode contribuir para minimizar os impactos negativos e servir como princípios norteadores para a implementação de ações mitigadoras. Assim, o objetivo desse trabalho é utilizar indicadores para avaliar o processo de expansão da pastagem no Pantanal de Cáceres-Mato Grosso no período de 1999 a 2014.

\section{MATERIAL E MÉTODO}

\section{Área de Estudo}

O Pantanal de Cáceres é uma das sub-regiões do Pantanal Mato-grossense, uma extensa planície alagável localizada na Bacia do Alto Rio Paraguai (BAP) a sudoeste do estado de Mato Grosso (Figura 1). A área de estudo corresponde a 9,01\% do Pantanal mato-grossense, totalizando 12.412,56 quilômetros quadrados, sua maior porção está 
localizada no município de Cáceres-MT, nas coordenadas geográficas 15³1'15" e $17^{\circ} 37^{\prime} 45^{\prime \prime}$ Latitude Sul e $58^{\circ} 32^{\prime} 30^{\prime \prime}$ e $57^{\circ} 21^{\prime} 55^{\prime \prime}$ Longitude Oeste, ocupando 50,87\% do território cacerense (NEVES; CRUZ; NEVES, 2008).

Figura 1 - Localização do Pantanal de Cáceres no estado de Mato Grosso

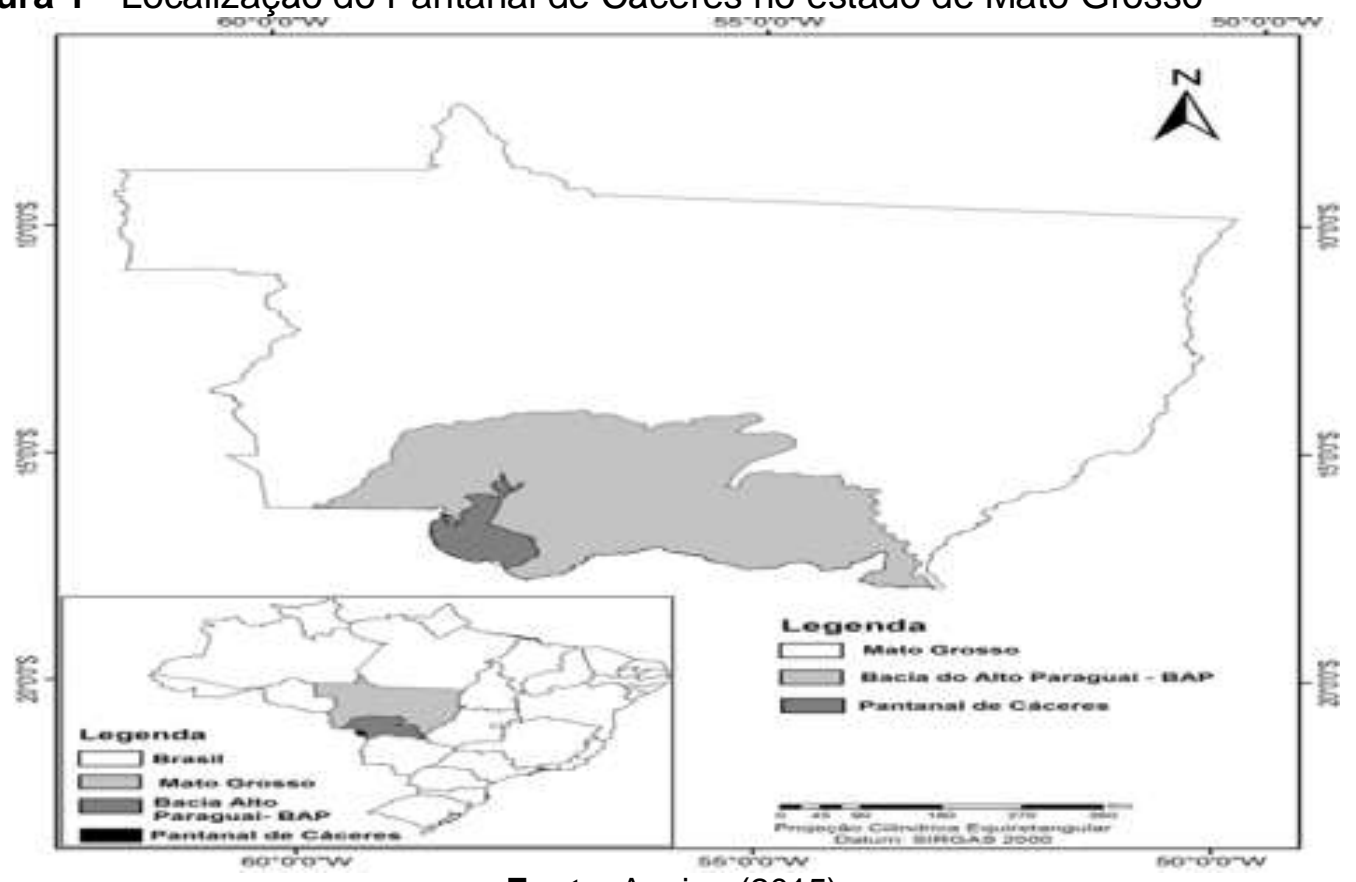

Fonte: Aquino (2015).

A fitofisionomia da região é composta por diferentes extratos vegetais tais como: Savana Arborizada, Savana Florestada e Savana Gramíneo-Lenhosa (IBGE, 2012). A temperatura média anual é de $22,6^{\circ} \mathrm{C}$ (BRASIL, 2014), índice pluviométrico de 1200 à 1500 milímetros anuais (NEVES; CRUZ; NEVES, 2008) e altitude variando entre de 90 a 200 metros (BRASIL, 1982).

O tipo de vegetação está associado ao solo da região que apresenta baixa fertilidade e é composto principalmente por Plintossolo (PL), Plantossolo (PT) e Areias Quartzosas (NeossoloQuartzarênico) com influência de processos hidromórficos (EMBRAPA, 2006; FERNANDES et al., 2007).

\section{Procedimentos Metodológicos}

Foram elaborados indicadores para avaliação da expansão da pastagem no Pantanal de Cáceres-MT, usando como referência os Indicadores para Avaliação do Potencial de Sustentabilidade Hídrica e Monitoramento da Cultura Canavieira - SISH (FERRAZ; SIMÕES; DUBREUIL, 2013). Os dados usados para o cálculo dos indicadores foram obtidos 
dos resultados da análise da área de estudo e aplicado nas fórmulas para obtenção dos índices.

A partir da coleta dos dados e das imagens adquiridas dos satélites Landsat5 e 8, sensor TM e OLI, respectivamente, foi possível mapear, identificar, selecionar e classificar as imagens que recobrem o Pantanal de Cáceres nos anos de 1999, 2004, 2009 e 2014. Foram usadas três classes de uso da terra (Pastagem, Vegetação Natural Florestal e Savana Arborizada + Savana Gramíneo-Lenhosa) definidas a partir do Manual de Uso da Terra (IBGE, 2006).

A pastagem pode ser formada por gramíneas nativas da região e gramíneas exóticas. A pastagem composta por gramíneas nativas compõe a fitofisionomia Savana Arborizada + Savana Gramíneo-Lenhosa ( $\mathrm{Sa}+\mathrm{Sg}$ ), composta pela junção de duas classes de vegetação que possuem campos nativos abertos, vegetação arbórea espaçada e pouco densa, com árvores de pequeno porte. A pastagem exótica é formada por espécies de forrageiras cultivadas ou introduzidas, algumas originadas da África como o Andropogomgayanus (SANTOS et al., 2005). O trabalho foi dividido em etapas metodológicas, da seguinte forma:

$1^{\circ}$ etapa - Obtenção dos dados: para auxiliar na obtenção dos dados da área de estudo foi utilizada a análise da representação espacial por meio do Sistema de Informações Geográficas (SIG). As imagens selecionadas e mosaicadas foram adquiridas por meio do catálogo de imagens do Instituto de Pesquisas Espaciais (INPE) e do United StatesGeologicalSurvey (USGS, 2015) disponíveis gratuitamente na rede mundial de computadores. Foi realizado o recorte dos mapas com os limites territoriais (shapes) utilizando softwares Spring 5.2.7 e ArcGis 10.1. Foi também realizada a segmentação, pelo

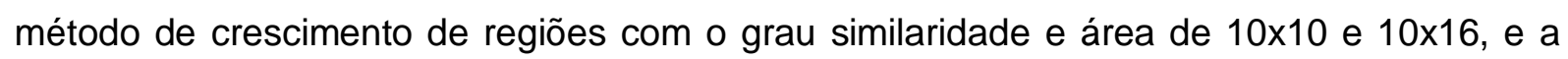
classificação supervisionada pelo método de Bhattacharya, com aceitação de 99\% (XAUD; EPIPHANIO, 2014). Foram geradas seis classes temáticas (Pastagem, Vegetação Natural Florestal, Savana Arborizada + Savana Gramíneo-Lenhosa, Usos Antrópicos, Queimada e Massa D'água), porém para a construção dos indicadores apenas foram consideradas as áreas de expansão.

$2^{\circ}$ etapa - Tratamento dos dados: com a construção de uma base de informação espacial foi possível fazer a quantificação utilizando os softwares Spring 5.2.7 e ArcMap 10.1, gerando as proporções respectivas de cada classe em hectares. As informações adquiridas nessa etapa foram organizadas em planilhas do Excel e utilizadas como base para o cálculo.

$3^{\circ}$ etapa - Extração dos dados para o cálculo dos indicadores: foi realizada a organização, tabulação e cálculo dos dados utilizando as fórmulas e os valores numéricos armazenados em Excel, considerando apenas as proporções e as classes temáticas de 
interesse para o estudo (Pastagem, Vegetação Natural Florestal e Savana Arborizada + Savana Gramíneo-Lenhosa) além da área total. As fórmulas dos índices, dos indicadores e os cálculos foram realizados em planilha do Excel/Windows Office/ Microsoft.

O grupo de indicadores criados para avaliar a expansão foi adaptado do trabalho de Ferraz, Simões e Dubreuil (2013) e expressam os índices avaliados, relacionando área de expansão, substituição e supressão (Quadro 1).

Quadro 1 - Relação de indicadores de expansão da pastagem

\begin{tabular}{|l|l|}
\hline Indicadores & Fórmulas \\
\hline IOP - Índice de Ocupação de Pastagem & IOP = Atp/Atu \\
IEP - İndice de Expansão de Pastagem & IEP = (Atp-Ata)/Atu \\
ISAP - Índice de Substituição de Pastagem & ISAP = Asp/Aep \\
ISNV- Índice de Supressão de Vegetação Natural Florestal & ISNV = Asv/Aep \\
\hline
\end{tabular}

Nota: Atp - Área total de Pastagem; Atu - Área total da unidade territorial; Ata - Área total da pastagem no ano anterior; Asp - área de substituição de Savana Arborizada + Savana GramíneoLenhosa, por Pastagem; Aep - Área de expansão da Pastagem; Asv - Área de substituição de Vegetação Natural Florestal. Fonte: Aquino (2015)

O $1^{\circ}$ Grupo de indicadores está relacionado às informações da área total em análise, que apresenta uma extensão territorial de 12.371,00 quilômetros quadrados. O grupo é composto pelo IOP e IEP, estes representam o índice de ocupação e expansão de pastagem na região dos últimos 15 anos, com o intervalo de tempo de cinco anos (1999, 2004, 2009 e 2014). O IOP foi extraído da equação que relaciona a área total de pastagem (Atp) dividida pela área total da unidade territorial (Atu). O IEP é obtido a partir da área total de pastagem (Atp) subtraída da área total de pastagens dos anos anteriores (Ata), dividido pela área total da unidade territorial (Atu).

Os valores que compõe os elementos das fórmulas foram gerados a partir da quantificação das classes em hectares, por meio da calculadora de atributos do ArqGis, a partir da classificação supervisionada das imagens.

O $2^{\circ}$ Grupo de indicadores, composto pelo ISAP e ISVN mostram a substituição da pastagem nativa $(\mathrm{Sa}+\mathrm{Sg})$ e a Vegetação Natural Florestal por pastagem exótica.O ISAP representa a área de substituição de Savana $(\mathrm{Sa}+\mathrm{Sg}$ ) por Pastagem (Asp/Aep). O ISVN corresponde à área de substituição de Vegetação Natural Florestal dividida pela área de expansão de pastagem (Asv/Aep).

O processo de avaliação da expansão de pastagem exótica na região do Pantanal de Cáceres foi dividido em três fases: (1) - Avaliação da área de ocupação e intensidade do processo de expansão da pastagem; (2) - Avaliação do processo de substituição da pastagem; (3) monitoramento do processo de expansão de pastagem exótica. Para o estudo da área em questão foi realizada uma análise comparativa do processo de expansão da pastagem no período descrito (1999, 2004, 2009 e 2014). 


\section{RESULTADOS E DISCUSSÃO}

A definição dos indicadores e de seus respectivos índices, adquiridos a partir da quantificação em hectares (ha) das classes geradas no período de estudo, permitiu avaliar a ocupação e expansão da pastagem (Tabela 1).

Tabela 1 - Áreas de ocupação das classes em hectares, índices de ocupação, expansão, substituição e supressão de pastagem

\begin{tabular}{cccccccc}
\hline \multicolumn{4}{c}{ Áreas em hectares (ha) } & \multicolumn{5}{c}{ Indicadores } \\
\hline Ano & Vegetação Nativa & Savana & Pastagem & IOP & IEP & ISAP & ISVN \\
\hline $\mathbf{1 9 9 9}$ & $609.123,55$ & $245.992,15$ & $148.434,21$ & 0,12 & 0,06 & 1,24 & 0,2831 \\
$\mathbf{2 0 0 4}$ & $596.130,22$ & $246.057,24$ & $273.815,83$ & 0,22 & 0,10 & 0,0 & 0,1036 \\
$\mathbf{2 0 0 9}$ & $585.683,00$ & $207.692,13$ & $314.848,29$ & 0,25 & 0,03 & 0,93 & 0,2546 \\
$\mathbf{2 0 1 4}$ & $424.358,12$ & $209.684,34$ & $418.837,35$ & 0,34 & 0,08 & $-0,01$ & 1,55 \\
\hline
\end{tabular}

Fonte: Aquino (2015).

A análise espaço-temporal das imagens do satélite Landsat e os levantamentos de campo possibilitaram quantificar e mapear as áreas de pastagem no Pantanal de Cáceres no período de 1999 à 2014, nos quais se pode observar a expansão (Figura 2).

O período em que houve maior destaque na ocupação de pastagem (IOP) foi entre 1999 e 2004, nesse período o aumento no índice foi de 83,33\%, já o período com maior expansão da pastagem (IEP) foi entre os anos de 2009 e 2014, com um aumento de $62,05 \%$.

Além da exploração da aptidão natural da região para o desenvolvimento da pecuária bovina, outros fatores como o desenvolvimento econômico também contribuíram para a ampliação das áreas de ocupação e foram responsáveis pelo crescimento registrado pelos indicadores ao longo dos anos. A implantação do abatedouro em 2004 na cidade de Cáceres aqueceu o desenvolvimento da atividade na região, bem como o aumento do rebanho e do desmatamento para cultivo de pastagens, assim nos anos de 2006 a 2012 o município de Cáceres alcançou boas colocações no ranking estadual dos maiores produtores de bovinos da planície pantaneira (MATO GROSSO, 2006).

Dados fornecidos pelo Instituto de Defesa Agropecuária (INDEA, 2015) mostram que houve evolução do rebanho de bovinos e bubalinos no município de Cáceres, no período de 2000 a 2014, de 636.517 para 1.020 .246 cabeças, o que corresponde a um aumento de $60,28 \%$. Na região do Pantanal de Cáceres houve também um número expressivo entre o ano de 2008 a 2012, de 328.957 para 389.835 cabeças, respectivamente, o que representa um acréscimo porcentual de 15,61\%. 
Figura 02: Distribuição das classes temáticas do uso e cobertura da terra, no Pantanal de Cáceres MT/Brasil, dos anos 1999, 2004, 2009 e 2014
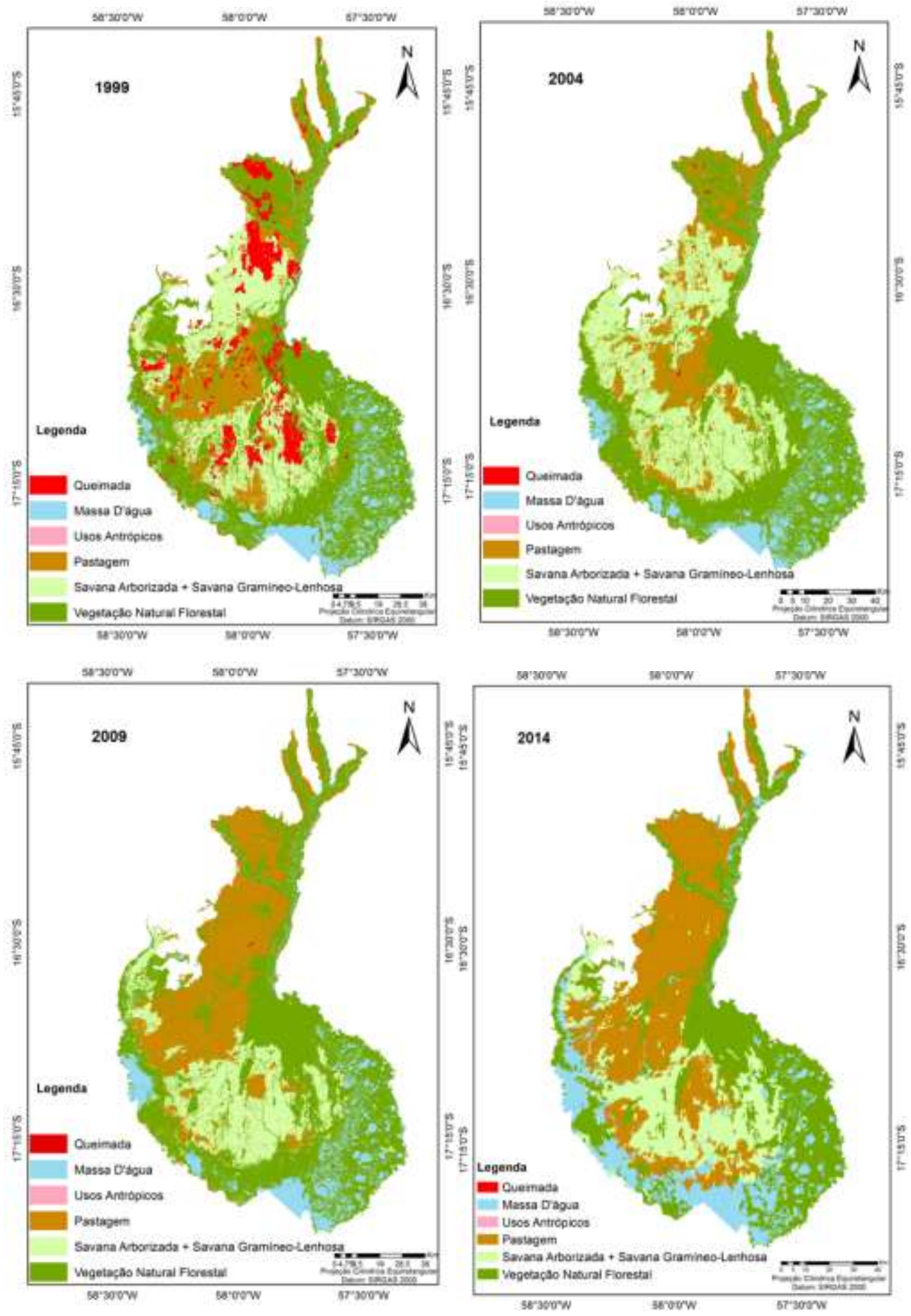

Fonte: Aquino (2015).

No período de estudo, a Vegetação Natural Florestal e a pastagem nativa composta por Savana Gramíneo-Lenhosa apresentaram uma expressiva redução, e o ISNV um aumento porcentual de $450,88 \%$. 
No Pantanal, a supressão da vegetação nativa, principalmente em áreas de cordilheiras, serve para implantação de pastagens exóticas, onde as espécies de forrageiras mais utilizadas e que se adaptam melhor às condições do solo arenoso e de baixa fertilidade são Brachiariahumidicola e B. decumbens (COMASTRI FILHO, 1997; CRISPIM; BARIONI JUNIOR; BRANCO, 2000).

Dessa forma, os indicadores de expansão e ocupação oscilaram de forma crescente, porém houve o decréscimo do indicador ISAP no período de 2004 e 2014, apresentando um índice zero e negativo, respectivamente; apesar de pouco representativo, deve-se ao fato da classe Sa+Sg apresentar um aumento em hectares do período de 1999 para 2004. Tal evento ocorreu em virtude do número de áreas da região tomadas pelas queimadas, condição ambiental que reduziu consideravelmente as áreas das outras classes refletindo nos resultados. O INPE registrou para o ano de 1999 o maior número de focos de queimadas dos últimos 21 anos para o Estado de Mato Grosso (INPE, 2015).

O aumento do IOP revela que ao longo do período de estudo houve expansão de áreas de pastagens a partir da supressão da Vegetação Natural Florestal. O relatório do mapeamento dos biomas brasileiros, divulgado pelo Ministério do Meio Ambiente em 2007, mostra que até 2002 a cobertura vegetal natural do Pantanal era de $86 \%$ e a cobertura vegetal antrópica de $12 \%$; o documento indica a atividade pecuária como principal atividade responsável pelo desmatamento (BRASIL, 2014).

Em estudo realizado no período 2008 a 2009, o mesmo projeto de monitoramento dos biomas brasileiros apontou que $15,30 \%$ do Pantanal apresentava áreas desmatadas e ainda destacava no estado de Mato Grosso o Pantanal de Cáceres como campeão no ranking de desmatamento (IBAMA, 2011).

Os indicadores de ocupação IOP e de supressão da Vegetação Natural Florestal ISVN foram crescentes para todo o período e demonstram influência de fatores externos que incentivaram o crescimento da economia local por meio da perspectiva em torno da cadeia produtiva (MATO GROSSO, 2010).

O registro do crescimento do IOP para o período estudado corresponde não somente à vocação e ao crescimento do mercado local, mas também a uma tendência refletida da economia brasileira. O Brasil é o segundo maior produtor e o maior exportador mundial de carne bovina (IBGE, 2006), e o sistema de produção é caracterizado por ser o mais barato do mundo, baseado no cultivo de pastagens, fato atribuído à sua extensão territorial com áreas teoricamente disponíveis e condições climáticas favoráveis (DIAS-FILHO, 2014).

No caso do Pantanal, o crescimento do IOP também corresponde ao diagnóstico realizado por Dias-Filho (2014) no qual escreve que áreas marginais de difícil acesso e com baixo potencial agrícola, por apresentarem solo pobre, são preferencialmente destinadas a formação de pastagens, além de sua aptidão natural. No Pantanal o pulso de alagamento 
sazonal permite a formação de pastagens naturais em períodos de estiagem (POTT; POTT, 1996).

Da mesma forma, o Instituto Brasileiro de Geografia e Estatística (IBGE, 1998) destaca que a base da economia da região é a criação extensiva de gado para corte, uma vez que a agricultura é pouco recomendada, devido principalmente às enchentes periódicas e aos solos pouco férteis.

Dos indicadores gerados, o ISNV apresentou um aumento de 450,88\% de supressão da Vegetação Natural Florestal. O aumento crescente do ISNV se deve ao acúmulo da interação de dois índices altos, redução da Vegetação Natural Florestal e expansão da pastagem. A supressão da Vegetação Natural Florestal na região do Pantanal é realizada para o plantio de pastagens exóticas. Silva et al. (2010) relatam que até o ano de 2008 houve redução da vegetação nativa do bioma do Pantanal da ordem de $15 \%$.

$O$ indicador de expansão IEP e substituição de pastagem (ISAP) também foram crescentes, porém com comportamento oscilatório. A oscilação desses indicadores, para os períodos analisados, deve-se ao fato da alteração dos dados que compõe os índices, fato que demonstra a necessidade de acompanhamento da dinâmica da região.

\section{CONCLUSÃO}

Os indicadores IOP e ISVN foram crescentes em todo o período de estudo. Os indicadores de expansão IEP e ISAP também apresentaram crescimento, porém com comportamento oscilatório, fato que pode ser atribuído à sazonalidade do ciclo das águas. Verificou-se que a expansão da pastagem exótica promove a supressão da Vegetação Natural Florestal e também a substituição da Savana Arborizada + Savana GramíneoLenhosa. A expansão das áreas de pastagem exóticas verificada no estudo corrobora com dados de instituições oficiais governamentais e demostra que o bioma está ameaçado pelo desenvolvimento da pecuária.

Os indicadores gerados estão sujeitos a oscilações, fato que ressalta a necessidade do acompanhamento da dinâmica fitofisionômica da região, que varia de acordo com as condições edafoclimáticas de cada período.

O uso de imagens obtidas através dos satélites Landsat 5 e 8 viabilizaram a realização do estudo por meio da análise das classes temáticas. O presente estudo permitiu utilizar indicadores que auxiliam na avaliação do estado de um ambiente complexo, o Pantanal, e que podem contribuir como norteadores para a tomada de decisão dos gestores públicos. 


\section{REFERÊNCIAS}

ABREU, U. G. P.; ROSA, A. N. Núcleos de seleção em bovinos de corte no Pantanal. Corumbá: Embrapa Pantanal, 2007. Disponível em:

<http://www.infoteca.cnptia.embrapa.br/bitstream/doc/812444/1/DOC88.pdf>. Acesso em: 12 set. 2014.

AQUINO, H. R. R. C. Análise da modificação ambiental do pantanal de Cáceres-Mato Grosso. 2015. 57 f. Dissertação (Mestrado em Ambiente e Sistemas de Produção Agrícola) - Universidade do Estado de Mato Grosso, Cuiabá.

BOVE, C. P. et al. Hidrófitas fanerogâmicas de ecossistemas aquáticos temporários da planície costeira do Estado do Rio de Janeiro, Brasil. Acta Botânica Brasílica, Belo Horizonte, v. 17, n. 1, p. 119-135, 2003.

BRASIL. Ministério das Minas e Energia. Departamento Nacional da Produção Mineral. Projeto RADAMBRASIL. Levantamento de recursos naturais: folha SD. 21: Cuiabá. Rio de Janeiro, 1982.

Ministério do Meio Ambiente. Biomas. Pantanal. Disponível em:

<http://www.mma.gov.br/biomas/pantanal\#footer>. Acesso em: 24 ago. 2014.

Ministério do Meio Ambiente. Convenção Sobre Diversidade Biológica - CDB.

Decreto Legislativo no 2, de 1994. Disponível em:

<http://www.mma.gov.br/informma/item/7513-conven\%C3\%A7\%C3\%A3o-sobre-diversidadebiol\%C3\%B3gica-cdb>. Acesso em: 24 abr. 2018.

Ministério do Meio Ambiente. Mapeamento dos Biomas Brasileiros - PROBIO.

Levantamento e mapeamento dos remanescentes da cobertura vegetal do bioma Pantanal. 2007. Relatório final.

COMASTRI FILHO, J. A. Pastagens Cultivadas. In: EMBRAPA. Centro de Pesquisa Agropecuária do Pantanal. Tecnologia de Informação para pecuária de corte no Pantanal. Corumbá: Embrapa Pantanal, 1997. p. 21-47.

CRISPIM, S. M. A.; BARIONI JUNIOR, W.; BRANCO, O. D. Comportamento produtivo das braquiárias no Pantanal - MS. Brasil. In: SIMPÓSIO SOBRE RECURSOS NATURAIS SOCIO-ECONÔMICOS DO PANTANAL, 3., 2000, Corumbá. Anais... Corumbá: Embrapa Pantanal, 2000. p. 1-10.

DIAS-FILHO, M. B. Diagnóstico de pastagem no Brasil. Belém: Embrapa Amazônia Oriental, 2014.

EMBRAPA. Centro Nacional de Pesquisa de Solos. Sistema brasileiro de classificação de solos. Rio de Janeiro, 2006.

FERNANDES, F. A. et al. Atualização do mapa de solos da planície pantaneira para o sistema brasileiro de classificação de solos. Corumbá: Embrapa Pantanal, 2007. Disponível em: <http://www.cpap.embrapa.br/publicacoes/download.p hp?arq_pdf=COT61>. Acesso em: 25 maio 2014.

FERNANDES, I. M.; SIGNOR, A. C.; PENHA, J. Biodiversidade no Pantanal de Poconé. Cuiabá: Centro de Pesquisa do Pantanal, 2010. p.36-38.

FERRAZ, R. P. D.; SIMÕES, M.; DUBREUIL. Indicadores para avaliação do processo de expansão da cultura canavieira no sul do estado de Goiás. Revista Brasileira de Ciências Ambientais, São Paulo, v. 29, p. 76-86, 2013.

FIGUEIREDO, M. A. G. Uso de indicadores ambientais no sistema de gerenciamento ambiental. Produção, Belo Horizonte, v. 6, n. 1, p. 33-34, jul. 1996. Disponível em: <http://www.scielo.br/pdf/prod/v6n1/v6n1a02> Acesso em: 9 ago. 2014. 
FREITAS, G. K. Invasão biológica pelo capim-gordura (MelinisminutifloraBeauv.) em um fragmento de cerrado (A.R.I.E. Cerrado Pé-de-Gigante, Santa Rita do Passa Quatro, SP). 1999. 157 f. Dissertação (Mestrado em Ecologia Geral) - Universidade de São Paulo, São Paulo, 1999.

PIVELLO, V.R. O desafio da conservação dos recursos naturais na região: a ameaça das gramíneas exóticas à biodiversidade. 2005. Disponível em: <http://ecologia.ib.usp.br/lepac/conservacao/Artigos/cap22.pdf>. Acesso em: 18 jun. 2015.

FREITAS, R. M. et al. Virtual laboratory of remote sensing time series: visualization of MODIS EVI2 data set over South America. Journal of Computational Interdisciplinary Sciences, São José dos Campos, v. 2, n. 1, p. 57-68, 2011.

GUGLIERI, A.; CAPORAL, F. J. M.; SIAMARELLI, A. Modelo de distribuição geográfica de cinco gramíneas invasoras em Mato Grosso do Sul, Brasil. In: SIMPÓSIO DE GEOTECNOLOGIA DO PANTANAL, 2., 2009, Corumbá. Anais... Corumbá: Embrapa Agropecuária/ INPE, 2009. p. 834-843.

IBAMA - Instituto Brasileiro do Meio Ambiente. Relatório 2008-2009. 2011. p. 7-45.

Disponível em: <http://siscom.ibama.gov.br/monitora_biomas/PMDBBS\%20-

\%20PANTANAL.html> Acesso em: 27 dez. 2015.

IBGE. Censo agropecuário 1995-1996. Rio de Janeiro, 1998. Censo agropecuário n. 24, Mato Grosso.

Manual técnico da vegetação brasileira. Rio de Janeiro, 2012.

Manual técnico de uso da terra. Rio de Janeiro, 2006.

INDEA - Instituto de Defesa Agropecuária do Estado de Mato Grosso. Extrato administrativo da evolução do rebanho do Município de Cáceres dos últimos 10 anos. Cáceres - MT, 2015.

INPE - Instituto Nacional de Pesquisas Espaciais. Portal. Monitoramento de queimadas e incêndios. Disponível em: <http://www.inpe.br/queimadas>. Acesso em: 23 dez. 2015.

MATO GROSSO. Secretaria de Planejamento de Estado. Mato Grosso em números. Edição 2010. Disponível em: <www.seplan.mt.gov.br/>. Acesso em: 10 abr. 2014.

Mato Grosso em números: um diagnóstico da realidade de Mato Grosso. Edição 2006. Disponível em: <www.seplan.mt.gov.br> Acesso em: 10 abr. 2014.

Relatório técnico: projeto de lei. 2004. Disponível em:

<http://www.seplan.mt.gov.br/arquivos/A_da54fd0cef9049f33059d79947da90cbRelatorio\%2 0Tecnico\%20ZONEAMENTO.pdf>. Acesso em: 20 abr. 2014.

NEVES, S. M. A. S.; CRUZ, C. B. M.; NEVES, R. J. Operacionalização de propostas de zoneamento turístico do Pantanal de Cáceres/MT, com suporte nas geotecnologias. Ciência Geográfica, Bauru, v. 18, p. 76-86, 2008.

POTT, A.; POTT, V. J. Flora do Pantanal, listagem atual de fanerógamas. In: SIMPÓSIO SOBRE RECURSOS NATURAIS E SÓCIO-ECONÔMICOS DO PANTANAL, 2., 1996, Corumbá. Anais... Corumbá: Embrapa, 1996. p. 297-325.

REBELLATO, L. Padrões sazonais e espaciais de distribuição e diversidade de herbáceas no Pantanal de Poconé - MT. 2010. Tese (Doutorado em Ecologia, Conservação e Manejo da Vida Silvestre) - Universidade Federal de Minas Gerais, Belo Horizonte.

RODRIGUES, F. H. C. et al. Revisão do conhecimento sobre ocorrência e distribuição de mamíferos do Pantanal. Corumbá: Embrapa Pantanal, 2002. 
SANTOS, A. S. et al. Substituição de pastagens nativa de baixo valor nutritivo por forrageiras de melhor qualidade no Pantanal. Corumbá: Embrapa, 2005. (Circular Técnica, n. 62, p. 1-5).

SILVA, G. B. S. et al. Discriminação da cobertura vegetação do cerrado mato-grossense por meio de imagens MODIS. Pesquisa Agropecuária Brasileira, Brasília, v. 45, n. 2, p. 186194, fev. 2010.

SILVA, J. S. V. et al. Projeto Geo MS: cobertura vegetal e uso da terra do Estado de Mato Grosso do Sul. Campinas: Embrapa Informática Agropecuária, 2011.

USGS. Geological Survey. Serviço de Levantamento Geológico Americano. Aquisição de imagens orbitais digitais gratuitas do Satélite Landsat-8. Disponível em:

<http://landsat.usgs.gov>. Acesso em: 18 jan. 2015.

XAUD, M. R.; EPIPHANIO, J. C. N. Dinâmica do uso e cobertura da terra no sudeste de Roraima utilizando técnicas de detecção de mudanças. Acta Amazônica, Manaus, v. 44, n. 1, p. 107-120, 2014. 